\title{
Metabolic reprogramming as a feast for virus replication
}

\author{
K. POLCICOVA', L. BADUROVA ${ }^{2}$, TOMASKOVA ${ }^{1^{*}}$
}

${ }^{1}$ Institute of Virology, Biomedical Research Center Slovak Academy of Sciences, Dúbravská cesta 9, 84505 Bratislava, Slovak Republic; ${ }^{2}$ Department of Genetics, Faculty of Natural Sciences, Comenius University in Bratislava, Bratislava, Slovak Republic

\begin{abstract}
Summary. - Viral replication depends entirely on the energy and biosynthetic precursors supplied by the host cell metabolic network. Viruses actively reprogram host cell metabolism to establish optimal environment for their replication and spread. They stimulate the uptake of extracellular nutrients and predominantly modulate glucose, glutamine, and fatty acid metabolism to support anabolic metabolic pathways. Some viruses activate the process of aerobic glycolysis, divert the glycolytic carbon for biosynthetic reactions, and stimulate glutamine utilization to replenish tricarboxylic cycle intermediates. Others use glutamine carbon to promote de novo fatty acid synthesis, amino acid supply or glutathione production. The unique metabolic signature and different dependence of viral life cycle on the individual metabolic processes is therefore characteristic feature of almost each virus. Deeper understanding of how viruses alter cellular metabolic pathways or their upstream regulatory circuits may lead to development of more effective antiviral treatment strategies based on targeted metabolic inhibition.
\end{abstract}

Keywords: virus infection; metabolism; glycolysis; glutamine metabolism; fatty acid synthesis; metabolic reprogramming; virus-host interaction

\section{Introduction}

Viruses, as obligate intracellular parasites, do not have their own metabolism and thus are completely dependent on the metabolic machinery of the host cell. They require biosynthetic building blocks for generation of viral prog-

"Corresponding author. E-mail: jana.tomaskova@savba.sk; phone: +421-2-59302-421.

Abbreviations: 2 -DG $=$ 2-deoxy-D-glucose; AdV-5 = human adenovirus 5; AMPK = AMP-activated protein kinase; $\mathrm{DENV}=$ dengue virus; $\mathrm{EBV}$ = Epstein-Barr virus; GLS = glutaminase; $\mathrm{HIF}$ $(1,2)=$ hypoxia inducible factor $(1,2) ; \mathrm{HCMV}=$ human cytomegalovirus; $\mathrm{HCV}=$ hepatitis $\mathrm{C}$ virus; $\mathrm{HK} 2$ = hexokinase 2 ; HSV1 = herpes simplex virus 1 ; GLUT $(1,3,4)$ = glucose transporter $(1,3,4) ; \mathrm{IAV}=$ influenza A virus; ISKNV = infectious spleen and kidney necrosis virus; KSHV = Kaposi's sarcoma-associated herpesvirus; $\mathrm{LMP1}$ = latent membrane protein $1 ; \mathrm{MNV}=$ murine norovirus; $\mathrm{PFK} 1$ = phosphofructokinase-1; $\mathrm{PHD}(1,2,3)$ = prolylhydroxylase (1,2,3); $\mathrm{PI}$ K = phosphoinositide 3-kinase; $\mathrm{RV}=$ Rhinovirus; $\operatorname{SinV}=$ Sindbis virus; TCA cycle = tricarboxylic acid cycle; $\mathrm{VACV}=$ vaccinia virus; $\mathrm{WNV}=$ West Nile virus; $\mathrm{WSSV}=$ white spot syndrome virus; ZIKV = Zika virus eny and the energy that drives viral replication, assembly, and release. In order to fulfill these requirements, viruses have evolved different mechanisms to reprogram and exploit the host metabolism. In the past decade, research has focused on investigating how virus infection alters host metabolism to establish optimal environment for their replication. These studies revealed that virus infection triggers dramatic changes in a number of core cellular metabolic pathways, e.g. metabolism of glucose, glutamine and fatty acids (FA).

\section{Viruses and glycolysis}

Glucose oxidation is a major source of carbon and energy in mammalian cells during homeostasis. In the presence of oxygen, glucose is metabolized to pyruvate through glycolysis. Pyruvate is then transferred to mitochondria, where it is catabolized in the tricarboxylic acid cycle (TCA) and drives the electron transport chain to generate large amounts of ATP. In oxygen-limiting conditions, pyruvate is converted to lactate and transported out of the 
cell (anaerobic glycolysis). Most cancer and proliferating cells tend to convert glucose to lactate even in the presence of abundant oxygen, a process often referred to as aerobic glycolysis or the Warburg effect (Warburg et al., 1924; Vander Heiden et al., 2009).

When cells start to proliferate, there is an increased demand for nutrients for energy production as well as biosynthesis of novel macromolecules. Therefore, proliferating cells increase glucose uptake, which then channels into intermediate pathways. Increased amounts of glycolytic intermediates provide the precursors required for synthesis of nucleotides, amino acids, and lipids as well as for cellular redox homeostasis (Vander Heiden et al., 2009; DeBerardinis and Chandel, 2016).

Interestingly, viruses implement similar metabolic modifications in their host cells as tumor cells, and importantly, their replication often seems to depend on these changes. While several viruses induce common metabolic changes, precise metabolic reprogramming varies from virus to virus. The global virus-induced metabolic outcome is often highly context-dependent and may differ not only within the particular family of viruses but also among the types of infected cells. Moreover, remodeling of host cell metabolic processes appears to vary between DNA and RNA viruses.

\section{DNA viruses}

The members of the Herpesviridae family are among the most studied groups of viruses in terms of their impact on cellular metabolism. As early as 1962, Lewis and Scott found that herpes simplex virus 1 (HSV-1) virion production in HeLa cells is reduced in glucose-deficient medium(Lewis and Scott,1962). Later studies showed that treatment of HSV-infected cells with 2-deoxy-D-glucose (2-DG), a commonly used inhibitor of glycolysis, also impairs the production of infectious particles, likely due to reduced glycosylation of viral glycoproteins (Courtney et at., 1973; Knowles and Person, 1976). Abrantes et al. observed that HSV-1 increases glucose uptake, lactate production and ATP content, as well as phosphofructokinase-1(PFK-1) activity and expression. PFK-1 appears to be critical for HSV-1 replication because its knockdown affects the HSV1 life cycle (Abrantes et al., 2012). Metabolomic study, on the other hand, revealed that HSV-1 does not significantly affect glycolysis but induces pyruvate carboxylation to anaplerotically replenish TCA cycle metabolites, while redirecting other TCA cycle intermediates to pyrimidine biosynthesis (Vastag et al., 2011). Recent proteomic analysis of human corneal epithelial cells infected with HSV-1 showed a significant metabolic shift characterized by decreased TCA cycle activity and increased glycolysis upon infection (Cui et al., 2019). Since modulation of glycolysis during HSV-1 infection is variable under different circumstances, further studies are needed to decipher the mechanisms involved in virus-induced metabolic reprogramming and to determine whether glucose metabolism is important for HSV-1 replication.

Human cytomegalovirus (HCMV), a representative member of the $ß$-herpesvirus subfamily, induces markedly different changes in the host cell metabolism than HSV-1. The first hint that HCMV might manipulate hostcell metabolism came from early studies showing that glucose uptake was significantly increased in infected cells (Landini, 1984). The initial metabolomic study of virus-infected cells showed increased levels of metabolites involved in glycolysis, TCA cycle and pyrimidine nucleotide biosynthesis. Parallel microarray analysis revealed HCMV-induced transcriptional upregulation of specific glycolytic and TCA cycle enzymes, which mirrored the increases in metabolite levels (Munger et al., 2006). Subsequent carbon flux analysis showed that HCMV infection upregulates glycolytic fluxes as shown by the rapid conversion of labeled glucose into labeled glycolytic intermediates. In addition, infected cells exhibited an increased rate of lactate excretion (Munger et al., 2008). Consistent with the observed increases in glucose uptake, HCMV infection alters the expression of glucose transporters in infected human fibroblasts. Interestingly, HCMV eliminates the ubiquitously expressed glucose transporter type 1 (GLUT1) and simultaneously induces GLUT4, which has a much higher glucose transport capacity (Yu et al., 2011). Inhibition of GLUT4 not only decreases glucose consumption in infected cells but also significantly affects the formation of infectious progeny virions, suggesting that switching in GLUTs is necessary for efficient HCMV replication (Yu et al., 2011). Mechanistically, it appears that early viral protein synthesis and expression of major immediate-early protein IE72 is required to alter the expression of glucose transporters in infected cells (Yu et al., 2011). Subsequent research has shown that GLUT4 upregulation depends on HCMVmediated induction of carbohydrate-response elementbinding protein (ChREBP) (Yu et al., 2014). In addition, the increase in GLUT4 levels seems to be dependent on the activation of AMP-activated protein kinase (AMPK) induced by HCMV infection (McArdle et al., 2012). Previous work by McArdle et al. has also shown that the enzyme activating AMPK, calmodulin-dependent kinase (CaMKK), is an important factor for HCMV-mediated glycolysis activation and HCMV replication (McArdle et al., 2011). Inhibiting either AMPK or CaMKK blocks the virus-induced glucose uptake and glycolytic flux as well as the productive replication of the virus (McArdle et al., 2011, 2012). Although it is clear that glucose metabolism 
is important for HCMV infection, the exact mechanisms responsible for virus-induced activation of glycolysis are still not fully understood. However, a recent study by Rodríguez-Sánchez et al. (2019) revealed the importance of HCMV protein $\mathrm{U}_{\mathrm{L}} 38$ for virus-mediated metabolic reprogramming. They found that $\mathrm{U}_{\mathrm{L}} 38$ is necessary and sufficient to drive many metabolic changes, including glycolytic fluxes, through inhibition of TSC2, a negative regulator of protein kinase mTOR. Surprisingly, this process appears to be independent of activated mTOR.

Kaposi's sarcoma-associated herpesvirus (KSHV) is the etiologic agent of Kaposi's sarcoma (KS), the endothelialderived tumor, multicentric Castleman's disease or primary effusion lymphoma (Goncalves et al., 2017). Thus, the changes in host cell metabolism induced by KSHV are similar to those in tumors (Delgado et al., 2010; Yu et al., 2018). Latent KSHV infection of endothelial cells increases the uptake of glucose as well as lactic acid production, while oxygen consumption is decreased (Delgado et al., 2010). Consequently, it was shown that the expression of glucose transporter GLUT3, and the first rate-limiting enzyme of glycolysis, hexokinase 2 (HK2), is upregulated upon infection (Delgado et al., 2010). The metabolomics study revealed increased levels of major glycolytic intermediates in latently KSHV-infected endothelial cells (Delgado et al., 2012). Notably, inhibition of glycolysis has led to apoptosis of latently infected cells, indicating that induction of glycolysis is essential for survival of these cells (Delgado et al., 2010). Previous research has demonstrated that KSHV induces transcriptional activity of hypoxia inducible factors HIF-1 $\alpha$ and HIF-2 $\alpha$ in endothelial cells, which play a key role in the regulation of glucose metabolism (Carroll et al., 2006). Ma and colleagues have found that HIF-1 a promotes aerobic glycolysis in latently KSHV-infected endothelial cells through the upregulation of pyruvate kinase 2 (PKM2) (Ma et al., 2015). There is evidence that the KSHV-encoded miRNAs are sufficient to induce aerobic glycolysis in infected cells by targeting prolylhydroxylase 1(PHD1) and heat shock protein HSP9, resulting in stabilization of HIF-1 and subsequent metabolic reprogramming (Yogev et al., 2014). Although KSHV occurs predominantly in latent state in KS spindle cells, small amounts of infected cells undergo lytic replication, which is considered essential for oncogenesis and the maintenance of KS lesion (Leung et al., 2012; Sanchez et al., 2017). Sanchez et al. have found that glycolysis, glutaminolysis, and fatty acid synthesis are all required for maximal KSHV lytic production. Interestingly, glycolysis is necessary for early and late gene expression, since its inhibition blocks virus replication at a very early step (Sanchez et al., 2017).

Epstein-Barr virus (EBV) is another oncogenic herpesvirus associated with a number of malignances, includ- ing Burkitt's lymphoma and nasopharyngeal carcinoma. EBV, similar to KSHV, enhances glucose uptake and activates glycolysis (Thaker et al., 2019a). It has been shown that these changes are induced by EBV-encoded latent membrane protein 1 (LMP1) via fibroblast growth factor receptor 1 (FGRP1) signaling, and that this mechanism may play a role in the carcinogenic transformation of latently infected cells (Lo et al., 2015). Xiao et al. (2014) observed that LMP1 also elevates aerobic glycolysis by upregulation of HK2, while c-Myc has been shown to be essential for this upregulation. Another study provided evidence that LMP1 upregulates GLUT-1 transcription through mTORC1/NF- $\mathrm{BB}$ signaling, thus contributing to increased glycolysis (Zhang et al., 2017). Moreover, EBV has been shown to induce and stabilize HIF-1a (Wakisaka et al., 2004; Sung et al., 2017). Interestingly, EBV can use various mechanisms to stabilize HIF-1a. While LMP1 enhances the degradation of PHD1 and PHD3 by Siah1 E3 ubiquitin ligase (Kondo et al., 2006), EBV-encoded nuclear antigens EBNA-5 and EBNA-3 bind to and inactivate PHD1 and PHD2, respectively (Darekar et al., 2012). Both strategies lead to HIF-1a stabilization and subsequent aerobic glycolysis activation.

The human adenovirus 5 (AdV-5) is the most prominent representative of the Adenoviridae family that modulates cellular metabolism during infection. Similar to herpesviruses, adenovirus also induces glycolysis, mirroring the Warburg effect in cancer. In 1977, Bardell described increased glucose uptake and lactic acid production in AdV-5-infected epithelial cells (Bardell, 1977). Recent analyzes have shed light on the mechanisms, by which adenovirus induces metabolic reprogramming of host cells. Thai and colleagues have found that AdV-5-induced enhancement of glycolysis in epithelial cells is mediated by the viral gene product E4ORF1 (Thai et al., 2014). They have shown that E4ORF1 localizes to the nucleus and binds the transcription factor Myc to drive transcription of key glycolytic enzymes. As a result, E4ORF1 activation of Myc enhances the activity of the glycolytic pathway, increases nucleotide biosynthesis from glucose metabolites, and promotes optimal adenovirus replication (Thai et al., 2014). Study by Kong et al. has demonstrated that E4ORF1 targets also epidermal growth factor, insulin/insulin-like growth factor receptors, and phosphoinositide 3-kinase (PI3K) to mediate constitutive Myc expression. They suggested that constitutive Myc expression supports the formation of nuclear E4ORF1-Myc complexes, which activate Myc and consenquently enhance adenovirus replication (Kong et al., 2015).

While all of the above-mentioned viruses alter the metabolism of host mammalian cells, viruses that infect invertebrates are also capable of reprogramming metabolic pathways in a similar manner. The white spot syndrome 


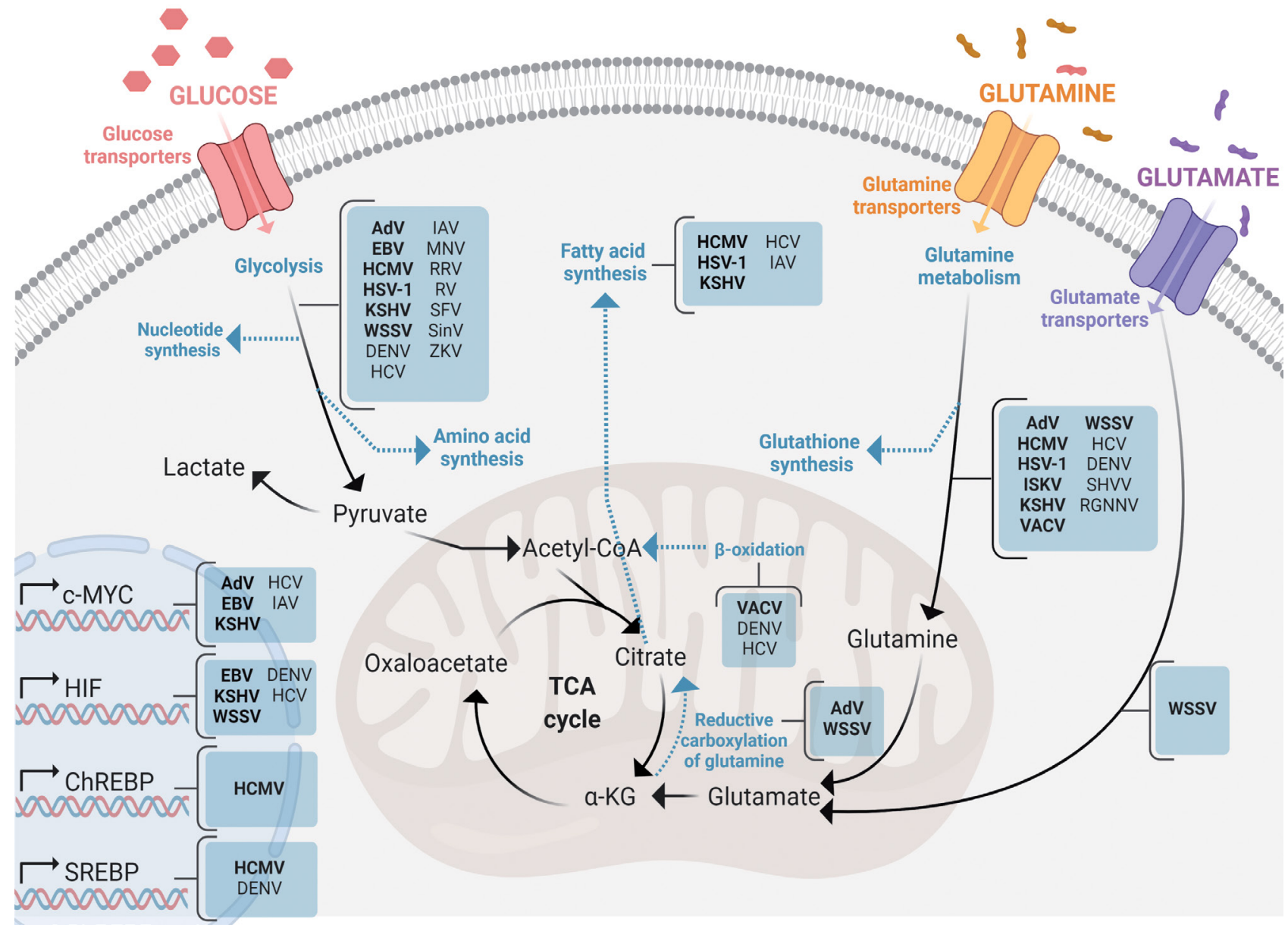

Fig. 1

Overview of the modulation of host cell metabolism by selected viruses Created with BioRender.com.

virus (WSSV), a member of the Nimaviridae family, is an example of an invertebrate virus that induces metabolic changes resembling Warburg effect in host cells (Chen et al., 2011; Su et al., 2014). WSSV infection of shrimps increases glucose consumption and lactate production during the viral genome replication stage. Notably, all observed changes disappeared at a later stage post infection (Chen et al., 2011). Further investigation of the changes in the proteome and the metabolome of WSSV-infected shrimp hemocytes confirmed a significant upregulation of the glycolytic markers. In addition, it was found that WSSV activates aerobic glycolysis in a PI3K-Akt-mTORdependent manner, which is essential for successful replication (Su et al., 2014).

\section{RNA viruses}

In contrast to the large DNA viruses discussed so far, the impact of RNA viruses on the host cell metabolism is more variable.

Early studies of poliomyelitis virus, a member of the Picornaviridae family, have shown that virus infection leads to increased glycolysis in monkey kidney tissue culture (Levy and Baron, 1957), and that the absence of glucose in the cell culture medium significantly reduces production of infectious virus progeny in HeLa cells (Eagle and Habel, 1956).

Rhinovirus (RV), another member of the Picornaviridae family, rapidly increases glucose uptake and GLUT1 expression in infected cells in PI3K-dependent manner (Gualdoni et al., 2018). Metabolomic analysis also revealed 
a critical role of glycogenolysis for virus replication. Consistent with these observations, the depletion of glucose from the culture medium as well as inhibition of glycolysis by 2-DG significantly impairs RV replication (Gualdoni et al., 2018).

Several viruses of the Flaviviridae family are powerful modulators of the metabolic state of the host cells. As many other viruses, dengue virus (DENV) stimulates and requires glycolysis for optimal replication. The expression of GLUT1 and HK2 is upregulated in DENV-infected human foreskin fibroblasts. As a result, glucose uptake during DENV infection is increased (Fontaine et al., 2015). In line with these observations, both withdrawal of glucose and 2-DG treatment lead to decreased DENV replication (Fontaine et al., 2015). Allonso et al. have demonstrated an interaction between glyceraldehyde-3-phosphate dehydrogenase (GAPDH) and viral NS1 protein. They have also shown that NS1 increases the glycolytic activity of GAPDH both in vitro and in vivo, suggesting that DENV actively promotes the glycolytic flux (Allonso et al., 2015). In addition, a recent study has shown that DENV induces HIF-1 $\alpha$ activation and anaerobic glycolysis markers in host cells in Akt-independent and ROS-dependent manner (Frakolaki et al., 2018).

Hepatitis C virus (HCV), a flavivirus distantly related to DENV, also induces glycolysis. It has been shown that the decrease in host cell oxidative phosphorylation caused by HCV proteins induces a metabolic shift toward glycolysis mediated by activation of HIF-1a (Ripoli et al., 2010). Global proteomic profiling of HCV-infected cells confirmed the increased expression of many glycolytic genes during early state of infection. In contrast, the early upregulation of glycolytic enzymes as well as other proteins involved in macromolecular biosynthesis was profoundly reduced at later stages of infection, suggesting metabolic shift from biosynthetic activities supporting viral replication and propagation to maintaining energy homeostasis and cell survival (Diamond et al., 2010). HCV appears to have a number of strategies to regulate host cell glycolysis. Viral protein NS5A has been shown to interact with HK2, which leads to its enhanced activity, resulting in increased glycolytic flux (Ramiere et al., 2014). On the other hand, microRNA 122, which directly targets PKM2, is sequestered by binding to several sites of HCV genome that may contribute to upregulation of this enzyme (Liu et al., 2014).

Zika virus (ZIKV), another member of Flaviviridae, differentially alters glucose metabolism during infection of human cells and mosquito cells. Although ZIKV-infection of both cell types leads to enhanced glycolysis, infection of human cells promotes increased glucose utilization in the TCA cycle, while in mosquito cells, glucose utilization is shifted toward the pentose phosphate pathway (Thaker et al.,2019b). In addition, ZIKV infection depletes nucleoside triphosphates and activates AMPK in human cells but not in mosquito cells. Consequently, AMPK activation contributes to apoptosis of ZIKV-infected human cells (Thaker et al., 2019b).

Murine norovirus (MNV) belongs to the Caliciviridae family and is commonly used as a model in human norovirus research. Recent metabolomic analysis of norovirusinfected cells revealed an increase in glycolysis, oxidative phosphorylation, and in the pentose phosphate pathway during MNV infection. Inhibition of glycolysis with 2-DG in macrophages confirmed that glycolysis is important for early stages of the MNV life cycle (Passalacqua et al., 2019). Moreover, MNV infection activates protein kinase Akt, while inhibition of Akt signaling reduces both cellular glycolysis and MNV replication, indicating a key role of PI3K/Akt pathway in the upregulation of host glucose metabolism during norovirus infection (Passalacqua et al., 2019).

Accumulating evidence suggests that glycolysis is also necessary for the efficient replication of alphaviruses. It has been reported that infection with Mayaro virus results in increased glucose consumption and glycolytic flux via activation of PFK1 in infected cells (El-Bacha et al., 2004). Similarly, Sindbis virus (SinV) infection also increases glucose uptake and lactate efflux in neuroblastoma cells (Silva da Costa et al., 2012). Further study has shown that treatment with inhibitors targeting different steps of glycolytic pathway resulted in a significant reduction of released SinV and Semliki Forest virus (SFV) (Findlay and Ulaeto, 2015). Recent research has shed more light on the mechanism, by which alphaviruses alter host metabolism. Mazzon and colleagues have found that SFV and Ross River virus (RRV) induce cellular glycolysis through hyperactivation of the PI3K/Akt pathway. This activation is initiated by binding of the YXXXM motif in viral protein $\mathrm{nsP} 3$ to the PI3K regulatory subunit p85 that triggers Akt signaling (Mazzon et al., 2018). Interestingly, SinV enhances glycolysis in the PI3K/Akt independent manner, since it lacks the YXXXM motif in nsP3 and has failed to induce Akt activation (Mazzon et al., 2018).

Influenza A virus (IAV), which belongs to the Orthomyxoviridae family, has also evolved strategies to use host glycolytic machinery for its own benefit. An early study in 1961 showed that IAV infection of chicken embryo cells increases glucose uptake and lactate production as soon as 1.5 hours after infection (Klemperer, 1961). Further metabolomic analysis revealed an increase in the uptake of extracellular glucose and in lactate release as well as elevated levels of upper glycolytic intermediates at 12 hours post infection in IAV-infected cells. On the other hand, IAV infection led to reduced levels of nucleotide triphosphates at the same time point (Ritter et al., 2010). 
As the observed changes coincided with the initiation of the cell death due to apoptosis, authors concluded that virus replication itself does not have a major impact on metabolism, but rather the onset of apoptosis induces this metabolic imbalance (Ritter et al., 2010). In contrast, more recent metabolomics study of IAV-infected cells showed altered activity of several metabolic pathways during the first cycle of virus replication, indicating the need for changes in cellular metabolism for optimal IAV replication (Tian et al., 2019). It has been found that inhibition of glycolysis significantly limits IAV replication, but addition of extracellular ATP restores influenza infection. These events occur in accordance with V-ATPase disassembly (Kohio and Adamson, 2013). Smallwood et al. have identified induction of glucose metabolism in the lungs of pediatric patients infected with respiratory pathogens. Using the proteomic approach, IAV-induced increase in c-Myc, glycolysis, and glutaminolysis were observed in primary human respiratory cells. The treatment with the PI3K/mTOR inhibitor BEZ235 abolished the transient induction of c-Myc and decreased the infectious progeny but did not affect the early stages of viral replication. In addition, BEZ235 significantly increased survival of mice and reduced viral titers in lungs (Smallwood et al., 2017). Interestingly, IAV NS1 protein activates PI3K/Akt pathway by direct interaction with the $\mathrm{p} 85$ subunit of PI3K via the YXXXM motif, hence using the same mechanism of PI3K activation as alphaviruses (Shin et al., 2007; Mazzon et al., 2018).

Although nearly all viruses investigated to date induce and require glycolysis, its exact role in viral replication and latent infection is not fully understood. As glucose uptake is important for bioenergetic demand and cellular biomass, increased glycolysis may be used by viruses as a rapid source of ATP or as a source of biomass for replication. Increased glucose uptake may also be needed to feed other metabolic pathways, such as the pentose phosphate, glutamine, and lipid pathways. Indeed, these virus-induced changes in glucose metabolism appear to play a critical role in successful infection, therefore it is important to understand the precise molecular mechanisms that drive this reprogramming.

\section{Viruses and glutamine metabolism}

Apart from glucose, the amino acid glutamine plays an equally important role as a bioenergetic and biosynthetic substrate during cell proliferation (Newsholme et al., 2003). Although glutamine is generally classified as a non-essential amino acid, during the intense proliferation with enhanced anabolic metabolism, its intake into cells is rapidly increased and it becomes conditionally essential
(Scalise et al.,2017). The metabolism of various tumor cells is specifically dependent on the exogenous glutamine supply and its deficiency limits their viability or their ability to proliferate. Tumor cells enhance glucose metabolism via aerobic glycolysis and redirect both glycolytic and TCA cycle intermediates into biosynthetic pathways in a process called cataplerosis. Glutamine serves as one of the carbon sources to anapleroticaly refill the depleted metabolites of the TCA cycle, and it is predominantly metabolized via glutaminolytic pathway (Lunt and Vander Heiden, 2011; DeBerardinis and Chandel, 2016). In the proliferating cells, glutamine can also support NADPH and glutathione (GSH) production, biosynthesis of lipids, amino acids and nucleotides or can serve as an antiport substrate for amino acids intake (Lunt and Vander Heiden, 2011). Since tumor and virus-infected cells have the same requirements in terms of enhanced bioenergetics and macromolecular synthesis, they share similarities not only in metabolic reprogramming of glucose metabolism but also in glutamine uptake and utilization. During evolution, various viral strategies and mechanisms have developed to alter glutamine metabolism of the host cells. Moreover, exogenous glutamine is a critical carbon source, whose intake is essential during replication of several viruses. Glutamine uptake and downstream metabolic pathways thus represent an interesting target of antiviral therapy.

\section{DNA viruses}

HCMV is one of the first herpesviruses deeply studied in terms of alterations in glutamine metabolism. A metabolomic analysis of HCMV-infected cells initially revealed the induction of glycolysis, TCA cycle and pyrimidine biosynthesis without affecting the concentration of any amino acids with the exception of alanine (Munger et al., 2006). However, a modification of the analysis using ${ }^{13} \mathrm{C}-$ labeled nutrients showed an increase in both glucose and glutamine uptake during HCMV infection. The glutaminederived carbons were incorporated into citrate, malate and $\alpha$-ketoglutarate, which indicates the engagement of glutamine in the anaplerosis of TCA cycle (Munger et al., 2008). Chambers et al. examined the molecular mechanism of HCMV-induced changes in glutamine metabolism and noticed increased activity of glutaminolytic enzymes converting glutamine to $\alpha$-ketoglutarate, i.e. glutaminase (GLS) and glutamate dehydrogenase (GDH) (Chambers et al., 2010). The function of glutamine during HCMV infection is mainly associated with supplementing TCA cycle intermediates, maintaining continuous ATP production in mitochondria and thus allowing to use glucose carbon to support FA synthesis (Munger et al. 2008; Chambers et 
al., 2010). The replication of HCMV also turned out to be glutamine-dependent as cultivation in glutamine-free medium completely abolished infectious virus production (Chambers et al., 2010). Viral molecular mechanisms responsible for the observed modulations of glutaminolysis are generally almost unknown or unclear. Although it has been shown that HCMV $\mathrm{U}_{\mathrm{L}} 38$ protein plays a critical role not only in the metabolic reprogramming of glycolysis but also in the induction of glutamine consumption through inhibition of TSC2. (Rodríguez-Sánchez et al., 2019).

As discussed earlier, a metabolomic screening of HSV-1-infected cells revealed virus-induced synthesis of pyrimidines mainly via cataplerosis of glucose-derived oxaloacetate from TCA cycle. Thus, glutamine is used as an anaplerotic substrate to feed the TCA cycle intermediates. Moreover, an experiment with ${ }^{13} \mathrm{C}$-labeled glutamine carbons revealed its direct contribution to aspartate production to support pyrimidine biosynthesis alongside with glucose (Vastag et al., 2011). The depletion of glucose or both glucose and glutamine from media during HSV-1 infection led to major reduction in virus production, suggesting the essential function of glucose in the life cycle of HSV-1. The glutamine starvation alone did not cause a reduction in HSV-1 progression. However, the HSV-1 replication in media lacking both glutamine and serum was significantly decreased (Lewis and Scott, 1962). The opposite influence of glutamine or both glutamine and serum starvation on HSV-1 propagation was probably caused by the use of non-dialyzed serum that contained residual amount of glutamine that could be sufficient to support virus replication. Despite the results of the aforementioned study, glutaminolysis is likely to play an essential role in HSV-1 life cycle, as pharmacological inhibition of GLS significantly reduced infectious virus production (Thai et al., 2015). Moreover, HSV-1-infected cells showed a higher rate of glutamine consumption compared to non-infected control (Thai et al., 2015).

While the first studies investigating the effect of KSHV infection on the host cell metabolism showed a global induction of aerobic glycolysis and FA synthesis, the metabolomic approach also identified a significant increase in glutamine level during KSHV infection (Delgado et al., 2010; 2012). A deeper investigation demonstrated that KSHV-infected cells induce expression of both glutamine importer ASCT2 (SLC1A5) and transcriptional regulator of glutaminolysis c-Myc. Moreover, KSHV-infected cells are "glutamine-addicted" since glutamine deprivation led to their apoptosis (Sanchez et al., 2015). A question worth considering is: why does KSHV need to alter the metabolism of the host cell during latent infection? It is possible that it works as a stress response during infection or it prepares the cellular microenvironment for survival and proliferation during KSHV infection (Lagunoff, 2016).
As mentioned earlier, virus-induced metabolic changes are not limited to latent KSHV infection. The induction of glycolysis, glutaminolysis and FA synthesis is also required during distinct stages of lytic KSHV infection. The presence of exogenous glutamine is mostly important for early gene translation, subsequent genome replication and late gene expression (Sanchez et al., 2017).

Many changes in the cells during adenovirus infection mirror those present in tumor cells (O'Shea et al., 2005). Despite the upregulation of aerobic glycolysis and glucose anabolic flux were the first observed signs of metabolic remodeling induced by AdV-5 infection, glutaminolysis was later shown to be equally important (Thai et al., 2014; 2015). AdV-5 induces the consumption of glutamine very early after infection. Moreover, AdV-5 infection causes increased expression of GLS and glutamine transporters ASCT2 (SLC1A5) and LAT1 (SLC7A5). The overall activation of glutamine metabolism in AdV-5-infected cells is strongly dependent on virus-induced c-Myc expression (Thai et al., 2015). Interestingly, the glutamine catabolism during AdV-5 infection is driven via reductive carboxylation pathway (Thai et al., 2015). Reductive carboxylation is a typical feature of cancer cells exposed to hypoxic conditions or cancer cells with defective mitochondrial oxidative function (Metallo et al., 2011; Mullen et al., 2011; Wise et al., 2011). This pathway utilizes glutamine to $\alpha$-ketoglutarate that is further reductively carboxylated against the conventional flow of TCA cycle to isocitrate and citrate. Citrate is shunted out the mitochondria, where it can be used to generate acetyl-CoA and oxaloacetate, the cataplerotic substrates for cellular biosynthesis (Mullen et al., 2011; Wise et al., 2011). Reductive carboxylation of glutamine to citrate can also take place in cytosol using different set of enzymes (Metallo et al., 2011). The labeling of glutamine carbons in AdV-5-infected cells also revealed its contribution to hexosamine biosynthetic pathway as well as aspartate, asparagine and proline synthesis (Thai et al., 2015). The importance of glutamine for AdV-5 was demonstrated by a glutamine starvation experiment and a pharmacological inhibition of GLS. Both conditions resulted in a significant decrease in viral titer (Thai et al., 2015). Moreover, the "glutamine addiction" was also shown to be characteristic for oncolytic adenoviruses, which could possibly explain their selectivity for the tumor environment (Dyer et al., 2019).

Vaccinia virus (VACV) belonging to the Poxviridae family has developed a specific interaction with the metabolism of the host cell. Even though VACV infection contributes to HIF-1a stabilization and increased transcription of several HIF-1-responsive genes, glycolysis is presumably dispensable for the viral life cycle (Mazzon et al., 2013; Fontaine et al., 2014). Glutamine, but not glucose, serves as the most important carbon source ensuring 
the formation of VACV infectious virions (Fontaine et al., 2014). Interestingly, the viral protein $\mathrm{C} 16$ was shown to be essential for the induction of glutamine metabolism, probably due to C16-triggered stabilization of HIF-1a. This observation shed light on the first molecular component explaining the basis of the VACV interaction with cellular metabolism (Mazzon et al., 2013, 2015). The upregulation of the glutamine intake during VACV infection is particularly important for the proteosynthesis, since the synthesis of early and late viral proteins is diminished in glutamine-free conditions (Fontaine et al., 2014). This raises the question whether the contribution of glutamine to viral protein synthesis in infected cells is direct, as a source of amino acids, or indirect, in the form of TCA cycle intermediates and energy supply. The experimental data originally provided evidence for the function of glutamine as an anaplerotic substrate for TCA cycle during VACV infection. However, the addition of TCA cycle intermediates to glutamine-free media did not entirely restore the infectious virus production, suggesting other putative functions of glutamine beyond anaplerosis (Fontaine et al., 2014). Subsequently, a recent study revealed the major function of glutamine during VACV infection besides its involvement in TCA cycle anaplerosis. The VACV replication and infectious virus production can be fully rescued by asparagine supplementation. Thus, glutamine serves as an essential precursor for asparagine synthesis that is indispensable during VACV protein production. Since asparagine can only be produced in the presence of glutamine, the latter becomes a limiting element for VACV replication (Pant et al., 2019).

Infectious spleen and kidney necrosis virus (ISKNV) is a member of the Iridoviridae family that includes viruses causing systemic infectious diseases of both marine and freshwater fish (Wang et al., 2007). Even though ISKNV is a non-human pathogen, it alters host cellular metabolic pathways in a way similar to human viruses. ISKNV infection of Chinese perch brain cells predominantly affects the glutaminolytic pathway. Glutamine serves as an important carbon source that replenishes TCA cycle intermediates, supports cellular ATP production and contributes to GSH synthesis during ISKNV infection (Fu et al., 2017). A further study of metabolomic changes during ISKNV infection revealed that glutamine is particularly important at later stage of infection. It presumably also promotes citrate production and lipid synthesis, and thus ensures ISKNV virion maturation (Fu et al., 2019). Moreover, inhibition of enzymes involved in the glutamine utilization or GSH production significantly reduced the ISKNV viral DNA copy number, suggesting the possible targets for the antiviral therapy that could reduce mortality and economic losses in the populations of Chinese perch ( $\mathrm{He}$ et al., 2000; Fu et al., 2017).
A systemic study of the metabolomic and proteomic alterations during WSSV infection identified changes not only in glucose metabolism, but also in glutaminolysis and biosynthesis of amino acids (Su et al., 2014). A deeper investigation of the WSSV-infected cells revealed an uncommon way of virus-induced hijacking of the glutamine metabolism. The WSSV infection predominantly stimulates the intracellular uptake of glutamate, which is further converted to $\alpha$-ketoglutarate to replenish TCA cycle intermediates. The authors of this study proposed a model of glutamate-driven anaplerosis that is essential for WSSV replication (Li et al., 2016). However, a recent metabolic tracer study showed that glutamine is also a substrate that is taken up by hemocytes during WSSV infection (He et al., 2019). The complex interaction between WSSV and glutamine metabolism is emphasized by the fact that the WSSV infection triggers not only the oxidative glutaminolytic pathway but also the reductive carboxylation of glutamine (He et al., 2019).

\section{RNA viruses}

The Picornaviridae family has a special position among the studies analyzing the interactions between RNA viruses and the host cell metabolism of glutamine. In 1956, Eagle and Habel were the first to notice the importance of glutamine supply for the virus replication. The ability of poliovirus to replicate in HeLa cells was significantly reduced in media free of glucose, glutamine or both components. Supplementing the poliovirus-infected cells starved for both glucose and glutamine with only glutamine increased the viral titer more significantly than the addition of only glucose, emphasizing the important role of glutamine in poliovirus life cycle (Eagle and Habel, 1956).

Rhinovirus is another representative of the picornaviruses that interferes with the glutamine metabolism of the host cells. The RV-infected cells are characterized by a metabolic shift toward anabolism that supports optimal virus production (Gualdoni et al., 2018). Even though the glucose uptake and enhanced glycogenolysis are the major alterations observed in cells during RV infection, glutamine plays particularly important function as well. The absence of either glucose or glutamine from cultivation media reduced viral replication, outlining the essentiality of both carbon sources for the RV life cycle (Gualdoni et al., 2018).

DENV and HCV are two prominent representatives of the Flaviviridae family that have developed slightly different strategies for the manipulation of the host cell metabolism. Both viruses largely affect the lipid metabolism to support and create suitable conditions for replica- 
tion (Heaton and Randall, 2010; Heaton et al., 2010; Syed et al., 2010; Chang et al., 2016). However, they differ in the dependence of replication and virus production on glutamine supply. The replication of HCV is more sensitive to glutamine withdrawal compared to virus production in glucose-free conditions (Lévy et al., 2017). The opposite is true for DENV, whose life cycle is more dependent on glucose supply (Fontaine et al., 2015). Metabolomic data from DENV-infected cells originally revealed increased concentration of both glutamine and glutamate, but further experiments showed that DENV infection inhibits oxidative metabolism of glutamine (Fontaine et al., 2015; Fernandes-Siqueira et al., 2018). The role of glutamine supply during DENV infection is probably associated with providing the amino group for various biosynthetic reactions (Fernandes-Siqueira et al., 2018). Fernandes-Siqueira et al. also proposed a potential engagement of glutamine in DENV-induced GSH synthesis (Fernandes-Siqueira et al., 2018). In contrast, Tian et al. showed DENV-induced drop in intracellular GSH level and a direct negative effect of GSH supplementation on DENV replication, suggesting that DENV infection is unlikely to stimulate the glutamine-coupled GSH synthesis (Tian et al., 2010).

The HCV infection is characterized by complex alterations of glutamine metabolism that strikingly resemble situation in tumor cells. HCV triggers cells to enhance glutamine uptake and induce expression of key enzymes involved in glutamine transport or utilization, e.g. LAT1 (SLC7A5), ASCT2 (SLC1A5) and GLS. Moreover, the observed changes in the expression of glutaminolytic genes are regulated by c-Myc, whose expression is also increased in HCV-infected cells (Lévy et al., 2017). The role of glutamine during HCV infection is mainly associated with TCA cycle anaplerosis and exchange for other amino acids (Lévy et al., 2017).

The induction of glutamine metabolism was also observed during infection with snakehead vesiculovirus (SHVV) that belongs to the family of Rhabdoviridae (Sun et al., 2016). SHVV is a fish virus that was originally isolated from the hybrid snakehead fish in China (Liu et al., 2015). Sun et al. showed that glutamine serves as an essential component for SHVV replication and infectious virus production. The addition of TCA cycle intermediates partially restored its propagation, suggesting an anaplerotic function of glutamine during infection (Sun et al., 2016). However, a recent study demonstrated that the inhibition of SHVV replication in glutamine-free conditions was also caused by the reduction of GSH synthesis and subsequent induction of autophagy (Li et al., 2019).

A red-spotted grouper nervous necrosis virus (RGNNV) is another unconventional non-mammalian RNA virus hosted by a variety of freshwater and marine fish. It belongs to the Nodaviridae family, whose members contrib- ute to severe fish infections that have a serious negative impact on the economy of aquaculture industry (Shetty et al., 2012). Similar to SHVV, the RGNNV infection also interferes with the glutamine metabolism of the host cells. Both glutamine deficiency and GLS inhibition significantly inhibit RGNNV replication (Asim et al., 2017). The metabolic pathways supporting the RGNNV life cycle due to glutamine intake are not yet fully understood. Recently, it was revealed that one of the glutamine functions in RGNNV-infected cells is to provide the carbon supply into TCA cycle (Asim et al., 2017).

\section{Viruses and fatty acid metabolism}

Lipids, as cellular components, are necessary at all steps of virus life cycle. They are required for the entry of the virus into the cell as part of cellular membranes; for the replication of the virus (e.g. structural remodeling of cellular membranes or as part of metabolic pathways included in virus replication); for maturation of viral proteins by means of their modification and for the production of mature particles of enveloped viruses and their infectivity. Last but not least, lipids may serve as a source of energy for replicating virus through $ß$-oxidation of FA.

As previously mentioned, virus-infected cells behave in many ways similar to tumor cells. This is true not only for glycolysis and glutamine metabolism, but also for FA metabolism, as many tumor cells were shown to have increased de novo FA synthesis (Kuhajda et al., 2000).

In contrast, FA synthesis is not essential for non-tumor cells (Munger et al.,2008) and most cells rely on the uptake of FA from the environment through specialized translocases (reviewed in Schwenk et al., 2010). However, FA of up to 16 carbons (palmitic acid) can be synthesized from the acetyl-CoA units by the actions of acetyl Co A carboxylase (ACC), and fatty acid synthetase (FASN). Longer FA are synthesized from the palmitate by elongases. In order to exploit the host lipid metabolism, viruses have adopted different ways to affect the biosynthesis of FA.

\section{DNA viruses}

As mentioned above, among the best studied viruses in terms of reprogramming of the cellular metabolism is HCMV. The study of the metabolome of both quiescent and actively growing HCMV-infected cells showed a dramatic increase in levels of acetyl-CoA at all time points after infection (Munger et al., 2006). Acetyl-CoA is a key molecule for all metabolic pathways, including central carbon metabolism, de novo lipid synthesis, and FA oxidation. Further studies of metabolic flux revealed 
an increased efflux of citrate from TCA cycle to the FA biosynthesis pathways, which is consistent with their upregulation (Munger et al., 2008). Additional support for the role of FA biosynthesis in HCMV replication comes from inhibitor studies. Treatment of infected cells with the inhibitor of either ACC or FASN (TOFA and C75, respectively) resulted in profound decrease in HCMV replication (Munger et al., 2008).

More recently, very long chain FA (VLCFA), e.g. saturated hexacosanoic acid, were found to be important for HCMV replication. In order to supplement their consumption, virus relies on the activity of cellular elongases (Koyuncu, 2013). This observation is also supported by metabolic flux experiments showing enhanced synthesis and elongation of FA as a prerequisite for VLCFA synthesis, which is required for virus envelope formation (Purdy et al., 2015). More detailed analysis of this phenomenon revealed that the activity of ELOVL7 isoform of elongase present in human cells is essential for virus-induced synthesis of VLCFA and for proper assembly of virus particles. HCMV also induces the activity of ELOVL7, which is likely to be mediated by the viral protein $\mathrm{U}_{\mathrm{L}} 38$ via mTOR and SREBP1 signaling(Purdy et al., 2015). Consistent with this, signaling through mTOR and SREBP2 was also found to be important for the activity of ACC in HCMV-infected human primary lung fibroblasts (Spencer et al., 2011).

Little information is available on how other herpesviruses alter lipid metabolism of infected cells, but it is known that HSV-1-induced changes in lipid metabolism are significantly different from those triggered by HCMV. The ${ }^{13} \mathrm{C}$-glucose labeling of HSV-1-infected cells suggests that the TCA cycle intermediates are not consumed for FA synthesis to the same level as in HCMV-infected cells (Vastag et al., 2011). This was further confirmed by pharmacological inhibition of the ACC, which suppressed the replication of HCMV to a much greater extent than the replication of HSV-1 (Munger et al.,2008; Vastag et al.,2011).

In the subfamily of $\gamma$-Herpesvirinae, Delgado et al. (2012) found that in immortalized endothelial cells latently infected with KSHV, the levels of many metabolites involved in FA synthesis were increased, among them long chain fatty acids e.g. palmitate, myristate, oleate and others. While this increase could be the result of stimulation of lipid degradation, analysis of FA precursor metabolites suggests it is rather the result of enhanced FA synthesis. Accordingly, the amount of lipid droplets used as "lipid storage" is increased in the cells latently infected with KSHV. When the effect of inhibitors of key enzymes in FA synthesis, ACC and FASN, was investigated, it was found that the infection with KSHV renders cells more sensitive to TOFA and C75. The treatment with either of these inhibitors led to significant increase in a cell death of infected cells via apoptosis compared to uninfected control. Addition of downstream metabolites (palmitic acid) improved the survival of infected cells. Altogether, this suggests that KSHV-infected cells require an increase in lipogenesis for their survival and for maintenance of KSHV latency (Delgado et al., 2012).

In cells with lytic replication of KSHV, treatment with the inhibitor TOFA resulted in decrease in virion production, as was observed also for HCMV (Munger et al., 2008; Sanchez et al., 2017). The virion production was rescued by the addition of palmitic acid, thus the FA synthesis is also required for optimal viral progeny production. Electronmicroscopic studies have suggested that the inhibition of FA synthesis results in a block of virus production at the stage of virion assembly and release (Sanchez et al., 2017).

Apart from herpesviruses, there are only few studies analyzing the interaction of other DNA viruses with lipid metabolism of the host cells. Perhaps the most studied among these viruses is the VACV. First studies on lipid metabolism and VACV appeared in 1980s and described fatty acid acylation of VACV proteins (Hiller and Weber, 1985; Franke et al., 1989). A more recent paper by Punjabi and Traktman (2005) analyzed the virus-host interactions and showed that the inhibition of FASN by cerulenin blocks the production of infectious progeny. More in-depth studies using inhibitors of ACC and FASN showed dramatically reduced viral yield, which could be rescued by the addition of downstream metabolite palmitate. This implies that the activity of both ACC and FASN, and, therefore, the de novo synthesis of FA, is necessary for successful replication of VACV (Greseth and Traktman, 2014). Additional analyses showed that inhibition of FA import into mitochondria or inhibition of mitochondrial $\beta$-oxidation resulted in reduced viral yield. Thus, it seems that VACV infection modulates the FA synthesis to provide the substrates for $\beta$-oxidation in mitochondria. Interestingly, FASN was found to localize near mitochondria in VACV-infected cells, supporting the hypothesis that FA are required as a source of energy for virus replication (Greseth and Traktman, 2014).

\section{RNA viruses}

As mentioned earlier, several members of the family Flaviviridae are powerful modulators of host cell metabolism. Since this family includes many important human pathogens, such as HCV or arboviruses West Nile virus (WNV), DENV and Tick-borne encephalitis virus (TBEV), a lot of attention is focused on the mechanisms used by these viruses to seize the host metabolism. A common feature of flavivirus infections is the remodeling of intracellular membranes upon infection, resulting in formation of characteristic membrane vesicles, which 
become "scaffolds" for the replication centers (reviewed in Apte-Sengupta et al., 2014). Formation of these replication centers likely requires modulation of the lipid metabolism, including the metabolism of FA.

The analysis of the lipid content of WNV-infected cells proved that the infection results in altered lipid profile of infected cells, thus suggesting that WNV modulates lipid metabolism of the host cell (Martin-Acebes et al., 2014). Therefore, the requirement of functional synthesis of FA was analyzed using FASN inhibitors. Inhibition of FASN activity resulted in reduced virus yield stemming from the reduced virus replication. In addition, FASN was partially relocalized in WNV-infected cells close to the sites of virus replication, supporting the hypothesis that WNV employs FASN for its replication (Martín-Acebes et al., 2011). To confirm these data, further studies using inhibitors of ACC were performed. Similar to the inhibition of FASN, the ACC inhibition resulted in lower virus yield. More detailed analysis showed that the remodeling of cellular membranes following the inhibitor treatment was not as profound as in untreated cells, and that viral RNA synthesis was also reduced under these conditions (Merino-Ramos et al., 2016). Taken together, the abovementioned facts provide evidence that the de novo FA synthesis is necessary for proper WNV replication. However, the underlying viral mechanisms responsible for the observed metabolic changes are not clear so far. Moreover, as WNV is a neurotropic virus and neuronal lipid membranes are enriched in sphingolipids, it is important to note that sphingolipids - e.g. ceramide and sphingomyelin - are enriched in WNV-infected cells (Martin-Acebes et al., 2014). Interestingly, mutations causing accumulation of sphingomyelin enable better replication of the virus (Martin-Acebes et al., 2016).

The interactions of DENV with the metabolism of the host cell also attract significant attention. Earlier studies trying to decipher the role of individual viral proteins in DENV life cycle showed that at least three cellular pathways are important for DENV replication - FA biosynthesis, actin polymerization and autophagy (Heaton et al., 2010). The need for FA synthesis was confirmed by experiments using FASN inhibitors, which significantly suppressed DENV replication. Further, it was shown that DENV protein NS3 forms a complex with FASN and recruits it to the replication complexes, probably via the interaction with Rab18 protein (Tang et al., 2014). NS3 is likely to stimulate FASN activity in infected cells; however, it does not affect its protein level. This is in contrast with $\mathrm{HCV}$, which promotes FASN accumulation (Yang et al. 2008; Heaton et al., 2010). Analysis of the transcription profile of genes involved in lipid metabolism showed significant changes in their expression during DENV infection. The upregulated genes include FASN, ACC1,
SREBP1c, diglyceride acyltransferase, fatty acyl oxidase and others (Tongluan et al., 2017).

Lipidomic analysis of mosquito cells infected with DENV and experimental inhibition of FASN lead to similar results as in mammalian cells, suggesting that the modification of the lipid metabolism is a characteristic feature of DENV infection and is not cell-specific or context-dependent (Perera et al., 2012). In addition to the enzymes involved in synthesis of FA, $\beta$-oxidation of FA is also required for DENV replication. This process seems to be triggered by the autophagy and consumes the FA obtained by the degradation of triglycerides from lipid droplets (Heaton and Randall, 2010).

HCV interactions with the host cell were also analyzed, including the impact of virus infection on the lipid metabolism. In HCV-infected cells, the protein level of FASN was found to be increased. Its importance for virus replication was further underlined by the observation that the presence of FASN inhibitor C75 causes reduction of cellular HCV core protein level and reduction of virus replication as measured by virus titer (Yang et al., 2008). An alternative approach of FASN knock-down using siRNA further supported the important role of FASN in HCV-replication (Yang et al., 2008). Additional support for the importance of FA synthesis in HCV replication comes from the data showing the decrease in HCV replication following treatment with TOFA, the ACC inhibitor (Kapadia and Chisari, 2005). A subsequent micorarray analysis of HCV-infected cells showed increase in the expression of genes involved in the synthesis and transport of FA (such as elongases, ACSL3, VLDLR) and decrease in the expression of genes involved in degradation and $\beta$-oxidation of FA (e.g. ACAT2) (Blackham et al., 2010). Lipidomic studies have confirmed previous evidence by detecting increased levels of longer fatty acids in HCVinfected cells, which may indicate increased synthesis of FA in cells, but also increased phospholipid degradation (Hofman et al.,2018). Other study by Diamond et al.(2010) analyzed the proteome and lipidome of HCV-infected cells and their findings support the enhanced synthesis of lipids and FA. They observed enhanced levels of a set of enzymes involved in FA synthesis, including fatty acid binding protein (FABP1) and FASN (Diamond et al., 2010). This suggests that upon infection, virus stimulates FA synthesis. In addition, decreased $\beta$-oxidation of FA, decreased acetyl-CoA pool, decreased carnitine-conjugated metabolites as well as increased FA level were observed in HCV-infected cells at later times of infection. Therefore, this virus is likely to use multiple approaches to ensure sufficient levels of FA needed for its optimal replication (Roe et al., 2011).

A recent study of the metabolome of IAV-infected human lung epithelial cells showed that FA synthesis, 
metabolism of arachidonic acid as well as FA elongation are among the most significantly altered metabolic pathways. However, more detailed analysis has not yet been performed (Tian et al., 2019). The metabolomic analysis of ferret tissues infected with IAV also showed significant changes in the lipid metabolism, including metabolism of arachidonic acid (Tisoncik-Go et al., 2016). The mechanisms underlying the metabolic changes caused by this virus remain to be discovered.

Similar to IAV, human coronaviruses (the family Coronaviridae) are also mostly respiratory viruses, some of them with the pandemic potential. SARS coronavirus 2 (SARS-CoV2) has recently claimed attention and its pandemic accelerates the research in this area with the aim to provide treatment for the disease. Only recently, Yan et al. characterized the lipidomic profile of cells infected with human coronavirus HCoV-229E. Among the three lipid classes significantly upregulated in these cells were lysophosphatidylcholine, lysophosphatidylethanolamine and FA. The highest fold induction among all lipids was observed for arachidonic acid. The levels of other FA, such as linoleic acids, palmitic acid and oleic acid, were also increased. Further metabolic analysis confirmed that the metabolic pathway of linoleic acid is significantly perturbed in cells infected by both the strain 229E and the highly pathogenic MERS-CoV. Therefore, it is likely that this modification is essential for their replication and pathogenesis (Yan et al., 2019). With the current high interest in coronavirus biology, we will probably soon gain more detailed information on interaction of this family of viruses with their host cell.

In addition to FA synthesis, viruses modulate other aspects of lipid metabolism, such as cholesterol metabolism, sphingolipid metabolism or lipid-modification of proteins (e.g. Chang 2009; Serquina et al., 2017; Benej et al. 2019; reviewed e.g. in Villareal et al., 2015; Osuna-Ramos et al., 2018); however, these are beyond the scope of this review.

\section{Conclusion}

Following infection of the host cell, virus seizes the cellular structures for its replication. To provide energy and building blocks for the replication, it also modifies the metabolism of its host. Current technical advance enables us to analyze these mechanisms on the molecular level, giving us a more detailed insight into fascinating world of virus-host interactions. Understanding similarities and disparities in virus-regulation of the metabolism of host cells allows improved targeting of drugs and hence the ability to treat more infections.
Acknowledgment. This work was supported by the joint grant agency of the Slovak Ministry of Education and Slovak Academy of Sciences VEGA (\#2/0030/19).

\section{References}

Abrantes JL, Alves CM, Costa J, Almeida FC, Sola-Penna M, Fontes CF, Souza TM, Biochim. Biophys. Acta, 1822 , 1198-1206, 2012. https://doi.org/10.1016/j.bbadis.2012.04.011

Allonso D, Andrade IS, Conde JN, Coelho DR, Rocha DC, da Silva ML, Ventura GT, Silva EM, Mohana-Borges R, J. Virol. 89, 11871-11883, 2015. https://doi.org/10.1128/ JVI.01342-15

Apte-Sengupta S, Sirohi D, Kuhn RJ, Curr. Opin. Virol. 9, 134-142, 2014. https://doi.org/10.1016/i.coviro.2014.09.020

Asim M, Jiang S, Yi L, Chen W, Sun L, Zhao L, Khan Khattak MN, Tu J, Lin L, Virus. Res. 227, 245-248, 2017. https://doi. org/10.1016/j.virusres.2016.11.007

Bardell D, Microbios 20, 139-144, 1977. https://doi.org/10.1055/ $\underline{\mathrm{s}-0028-1090368}$

Blackham S, Baillie A, Al-Hababi F, Remlinger K, You S, Hamatake R, McGarvey MJ, J. Virol. 84, 5404-5414, 2010. https://doi.org/10.1128/JVI.02529-09

Benej M, Danchenko M, Oveckova I, Cervenak F, Tomaska L, Grossmannova K, Polcicova K, Golias T, Tomaskova J, Front. Microbiol.10,2438,2019. https://doi.org/10.3389/ fmicb.2019.02438

Carroll PA, Kenerson HL, Yeung RS, Lagunoff M, J. Virol. 80, 10802-10812, 2006. https://doi.org/10.1128/JVI.0067306

Chambers JW, Maguire TG, Alwine, JC, J. Virol. 84, 1867-1873, 2010. https://doi.org/10.1128/JVI.02123-09

Chang KO, J. Virol. 83, 8587-8595, 2009. https://doi.org/10.1128/ JVI.00005-09

Chang ML, World J. Gastroenterol. 22, 1461-1476, 2016. https:// doi.org/10.3748/wig.v22.i4.1461

Chen IT, Aoki T, Huang YT, Hirono I, Chen TC, Huang JY, Chang GD, Lo CF, Wang, HC, J. Virol. 85, 12919-12928, 2011. https://doi.org/10.1128/JVI.05385-11

Courtney RJ, Steiner SM, Benyesh-Melnick M, Virology 52, 447455,1973. https://doi.org/10.1016/0042-6822(73)90340-1

Cui YH, Liu Q, Xu ZY, Li JH, Hu ZX, Li MJ, Zheng WL, Li ZJ, Pan HW, Exp. Eye Res. 185, 107664, 2019. https://doi. org/10.1016/j.exer.2019.05.004

Darekar S, Georgiou K, Yurchenko M, Yenamandra SP, Chachami G, Simos G, Klein G, Kashuba E, PLoS One 7, e42072, 2012. https://doi.org/10.1371/journal.pone.0042072

DeBerardinis RJ, Chandel NS, Sci. Adv.2,e1600200,2016.https:// doi.org/10.1126/sciadv.1600200

Delgado T, Carroll PA, Punjabi AS, Margineantu D, Hockenbery DM, Lagunoff M, Proc. Natl. Acad. Sci. USA 107, 1069610701, 2010 https://doi.org/10.1073/pnas.1004882107

Delgado T, Sanchez EL, Camarda R, Lagunoff M, PLoS Pathog. 8, e1002866, 2012. https://doi.org/10.1371/journal. ppat.1002866 
Diamond DL, Syder AJ, Jacobs JM, Sorensen CM, Walters KA, Proll SC, McDermott JE, Gritsenko MA, Zhang Q, Zhao R, Metz TO, Camp DG 2nd, Waters KM, Smith RD, Rice CM, Katze MG, Plos Pathog. 6, e1000719, 2010. https:// doi.org/10.1371/journal.ppat.1000719

Dyer A, Schoeps B, Frost S, Jakeman P, Scott EM, Freedman J, Jacobus, EJ, Seymour LW, Cancer Res. 79,331-345, 2019. https://doi.org/10.1158/0008-5472.CAN-18-1326

Eagle H, Habel K, J. Exp. Med. 104, 271-287, 1956. https://doi. org/10.1084/jem.104.2.271

El-Bacha T, Menezes MM, Azevedo e Silva MC, Sola-Penna M, Da Poian AT, Mol. Cell. Biochem. 266, 191-198, 2004. https://doi.org/10.1023/B:MCBI.0000049154.17866.00

Fernandes-Siqueira LO, Zeidler JD, Sousa BG, Ferreira T, Da Poian AT, mSphere 3, e00458-17, 2018. https://doi. org/10.1128/mSphere.00458-17

Findlay JS, Ulaeto D, J. Gen. Virol. 96, 2693-2696, 2015. https:// doi.org/10.1099/igv.0.000226

Fontaine KA, Camarda R, Lagunoff M, J. Virol. 88, 4366-4374, 2014. https://doi.org/10.1128/JVI.03134-13

Fontaine KA, Sanchez EL, Camarda R, Lagunoff M, J. Virol. 89, 2358-2366, 2015. https://doi.org/10.1128/JVI.02309-14

Frakolaki E, Kaimou P, Moraiti M, Kalliampakou KI, Karampetsou K, Dotsika E, Liakos P, Vassilacopoulou D, Mavromara P, Bartenschlager R, Vassilaki N, Cells 7, E241, 2018. https://doi.org/10.3390/cells7120241

Franke CA, Reynolds PL, Hruby DE, J. Virol. 63, 4285-4291, 1989. https://doi.org/10.1128/JVI.63.10.4285-4291.1989

Fu X, Guo X, Wu S, Lin Q, Liu L, Liang H, Niu Y, Li, N, Metabolites 9, E174, 2019. https://doi.org/10.3390/metabo9090174

Fu X, Hu X, Li N, Zheng F, Dong X, Duan J, Lin Q, Tu J, Zhao L, Huang Z, Su J, Lin, L, Oncotarget 8, 2400-2412, 2017. https://doi.org/10.18632/oncotarget.13681

Goncalves PH, Ziegelbauer J, Uldrick TS, Yarchoan R, Curr. Opin. HIV AIDS, 12, 47-56, 2017. https://doi.org/10.1097/ COH.0000000000000330

Greseth MD, Traktman P, PloS Pathog.10, e1004021, 2014. https:// doi.org/10.1371/journal.ppat.1004021

Gualdoni GA, Mayer KA, Kapsch AM, Kreuzberg K, Puck A, Kienzl P, Oberndorfer F, Frühwirth K, Winkler S, Blaas D, Zlabinger GJ, Stöckl J, Proc. Natl. Acad. Sci. USA 115, E7158-E7165, 2018. https://doi.org/10.1073/ pnas. 1800525115

He JG, Wang SP, Zeng K, Huang ZJ, Chan S-M, J. Fish Dis. 23, 219-222, 2000. https://doi.org/10.1046/j.13652761.2000.00213.x

He ST, Lee DY, Tung CY, Li CY, Wang HC, Front. Immunol. 10, 2102, 2019. https://doi.org/10.3389/fimmu.2019.02102

Heaton NS, Perera R, Berger KL, Khadka S, Lacount DJ, Kuhn RJ, Randall G, Proc. Natl. Acad. Sci. USA 107, 17345-17350, 2010. https://doi.org/10.1073/pnas.1010811107

Heaton NS, Randall G, Cell Host Microbe 8,422-432,2010. https:// doi.org/10.1016/j.chom.2010.10.006

Hiller G, Weber K, J. Virol. 55, 651-659, 1985. https://doi. org/10.1128/JVI.55.3.651-659.1985

Hofmann S, Krajewski M, Scherer C, Scholz V, Mordhorst V, Truschow P, Schobel A, Reimer R, Schwudke D, Herker E, Biochim. Biophys. Acta Mol. Cell Biol. Li- pids 1863, 1041-1056, 2018. https://doi.org/10.1016/j. bbalip.2018.06.002

Kapadia SB, Chisari FV, Proc. Natl. Acad. Sci. USA 102, 2561-2566, 2005. https://doi.org/10.1073/pnas.0409834102

Klemperer H, Virology 13, 68-77, 1961. https://doi.org/10.1016/ 0042-6822(61)90033-2

Knowles RW, Person S, J. Virol. 18, 644-651, 1976 https://doi. org/10.1128/JVI.18.2.644-651.1976

Kohio HP, Adamson AL, Virology 444, 301-309, 2013. https://doi. org/10.1016/i.virol.2013.06.026

Kondo, S Seo SY, Yoshizaki T, Wakisaka N, Furukawa M, Joab I, Jang KL, Pagano JS, Cancer. Res. 66, 9870-9877, 2006. https://doi.org/10.1158/0008-5472.CAN-06-1679

Kong K, Kumar M, Taruishi M, Javier RT, J. Virol. 89, 10774-10785, 2015. https://doi.org/10.1128/JVI.01463-15

Koyuncu E, Purdy JG, Rabinowitz JD, Shenk T, PLoS Pathog. 9, e1003333, 2013. https://doi.org/10.1371/journal. ppat.1003333

Kuhajda FP, Pizer ES, Li JN, Mani NS, Frehywot GL, Townsend CA, Proc. Natl. Acad. Sci. USA 97, 3450-3454, 2000. https://doi.org/10.1073/pnas.97.7.3450

Lagunoff M, Curr. Opin. Virol. 19, 45-49, 2016. https://doi. org/10.1016/j.coviro.2016.06.012

Landini MP, J. Gen. Virol. 65, 1229-1232, 1984. https://doi. org/10.1099/0022-1317-65-7-1229

Leung HJ, Duran EM, Kurtoglu M, Andreansky S, Lampidis TJ, Mesri EA, Antimicrob. Agents Chemother. 56, 5794-5803, 2012. https://doi.org/10.1128/AAC.01126-12

Levy HB, Baron S, J. Infect. Dis., 100, 109-118, 1957. https://doi. org/10.1093/infdis/100.2.109

Lévy PL, Duponchel S, Eischeid H, Molle J, Michelet M, Diserens G, Vermathen M, Vermathen P, Dufour JF, Dienes HP, Steffen HM, Odenthal M, Zoulim F, Bartosch B, Hepatology 65, 789-803, 2017. https://doi.org/10.1002/ hep.28949

Lewis VJ, Scott LV, J. Bacteriol. 83, 475-482, 1962 https://doi. org/10.1128/JB.83.3.475-482.1962

Li C, Sun L, Lin H, Qin Z, Tu J, Li J, Chen K, Babu VS, Lin L, Fish Shellfish Immunol. 86, 1044-1052, 2019. https://doi. org/10.1016/i.fsi.2018.12.041

Li CY, Wang YJ, Huang SW, Cheng CS, Wang HC, PLoS One 11, e0146902, 2016. https://doi.org/10.1371/journal. pone. 0146902

Liu X, Wen Y, Hu X, Wang W, Liang X, Li J, Vakharia V, Lin L, J. Gen. Virol. 96, 775-781, 2015. https://doi.org/10.1099/ vir. 0.000037

Liu AM, Xu Z, Shek FH, Wong KF, Lee NP, Poon RT, Chen J, Luk JM, PLoS One 9, e86872, 2014. https://doi.org/10.1371/ journal.pone.0086872

Lo AK, Dawson CW, Young LS, Ko CW, Hau PM, Lo KW, J. Pathol. 237, 238-248, 2015. https://doi.org/10.1002/path.4575

Lunt, SY, Vander Heiden MG, Annu. Rev. Cell Dev. Biol. 27, 441-464, 2011. https://doi.org/10.1146/annurev-cellbio-092910-154237

Ma T, Patel H, Babapoor-Farrokhran S, Franklin R, Semenza GL, Sodhi A, Montaner S, Angiogenesis 18, 477-488, 2015. https://doi.org/10.1007/s10456-015-9475-4 
Martin-Acebes MA, Blazquez AB, Jimenez de Oya N, EscribanoRomero E, Saiz JC, PLoS One 6, e24970, 2011. https://doi. org/10.1371/journal.pone.0024970

Martin-Acebes MA, Gabande-Rodriguez E, Garcia-Cabrero AM, Sanchez MP, Ledesma MD, Sobrino F, Saiz JC, J. Lipid. Res. 57, 422-432, 2016. https://doi.org/10.1194/ jlr.M064212

Martin-Acebes MA, Merino-Ramos T, Blazquez AB, Casas J, Escribano-Romero E, Sobrino F, Saiz JC, J. Virol. 88, 12041-12054, 2014. https://doi.org/10.1128/JVI.02061-14

Mazzon M, Castro C, Roberts LD, Griffin JL, Smith GL, J. Gen. Virol. 96, 395-407, 2015. https://doi.org/10.1099/ vir.0.069591-0

Mazzon M, Castro C, Thaa B, Liu L, Mutso M, Liu X, Mahalingam S, Griffin JL, Marsh M, McInerney GM, PLoS Pathog. 14, e1006835, 2018. https://doi.org/10.1371/journal. ppat. 1006835

Mazzon M, Peters NE, Loenarz C, Krysztofinska EM, Ember SWJ, Ferguson BJ, Smith GL, Proc. Natl. Acad. Sci. USA 110, 12444-12449, 2013. https://doi.org/10.1073/ pnas. 1302140110

Merino-Ramos T, Vazquez-Calvo A, Casas J, Sobrino F, Saiz JC, Martin-Acebes MA, Antimicrob. Agents Chemother. 60,307-315, 2016. https://doi.org/10.1128/AAC.01578-15

Metallo CM, Gameiro PA, Bell EL, Mattaini KR, Yang J, Hiller K, Jewell CM, Johnson ZR, Irvine DJ, Guarente L, Kelleher JK, Vander Heiden MG, Iliopoulos O, Stephanopoulos G, Nature 481, 380-384, 2011. https://doi.org/10.1038/ nature10602

McArdle J, Moorman NJ, Munger J, PLoS Pathog. 8, e1002502, 2012. https://doi.org/10.1371/journal.ppat.1002502

McArdle J, Schafer XL, Munger J, J. Virol. 85, 705-714, 2011. https://doi.org/10.1128/JVI.01557-10

Mullen AR, Wheaton WW, Jin ES, Chen PH, Sullivan LB, Cheng T, Yang Y, Linehan WM, Chandel NS, Deberardinis RJ, Nature 481, 385-388, 2011. https://doi.org/10.1038/ nature10642

Munger J, Bajad SU, Coller HA, Shenk T, Rabinowitz JD, PLoS Pathog. 2, e132, 2006. https://doi.org/10.1371/journal. ppat.0020132

Munger J, Bennett BD, Parikh A, Feng XJ, McArdle J, Rabitz HA, Shenk T, Rabinowitz JD, Nat. Biotechnol. 26,1179-1186, 2008. https://doi.org/10.1038/nbt.1500

Newsholme P, Procopio J, Lima MM, Pithon-Curi TC, Curi R, Cell Biochem. Funct. 21, 1-9, 2003. https://doi.org/10.1002/ cbf.1003

O'Shea CC, Oncogene 24,7640-7655,2005.https://doi.org/10.1038/ sj.onc. 1209047

Osuna-Ramos JF, Reyes-Ruiz JM, del Angel RM, Front. Cell. Infect. Microbiol. 8, 388, 2018. https://doi.org/10.3389/ fcimb.2018.00388

Passalacqua KD, Lu J, Goodfellow I, Kolawole AO, Arche JR, Maddox RJ, Carnahan KE, O'Riordan MXD, Wobus CE, mBio 10, e02175-18, 2019. https://doi.org/10.1128/ mBio.02175-18

Pant A, Cao S, Yang Z, J. Virol. 93, e01834-18, 2019. https://doi. org/10.1128/JVI.01834-18
Perera R, Riley C, Isaac G, Hopf-Jannasch AS, Moore RJ, Weitz KW, Pasa-Tolic L, Metz TO, Adamec J, Kuhn RJ, PLoS Pathog. 8, e1002584,2012. https://doi.org/10.1371/journal.ppat.1002584

Punjabi A, Traktman P, J. Virol. 79, 2171-2190, 2005. https://doi. org/10.1128/JVI.79.4.2171-2190.2005

Purdy JG, Shenk T, Rabinowitz JD, Cell Rep. 10, 1375-1385, 2015. https://doi.org/10.1016/j.celrep.2015.02.003

Ramière C, Rodriguez J, Enache LS, Lotteau V, André P, Diaz O, J. Virol. 88, 3246-3254, 2014. https://doi.org/10.1128/ JVI.02862-13

Ripoli M, D'Aprile A, Quarato G, Sarasin-Filipowicz M, Gouttenoire J, Scrima R, Cela O, Boffoli D, Heim MH, Moradpour D, Capitanio N, Piccoli C, J. Virol. 84, 647-660, 2010. https://doi.org/10.1128/JVI.00769-09

Ritter JB, Wahl AS, Freund S, Genzel Y, Reichl U, BMC Systems Biology 4, 61, 2010. https://doi.org/10.1186/1752-0509-4-61

Rodríguez-Sánchez I, Schafer XL, Monaghan M, Munger J, PLoS Pathog. 15, e1007569, 2019. https://doi.org/10.1371/ journal.ppat.1007569

Roe B, Kensicki E, Mohney R, Hall WW, PLoS One 6, e23641, 2011. https://doi.org/10.1371/journal.pone.0023641

Sanchez EL, Carroll PA, Thalhofer AB, Lagunoff M, PLoS Pathog. 11, e1005052, 2015. https://doi.org/10.1371/journal. ppat.1005052

Sanchez EL, Pulliam TH, Dimaio TA, Thalhofer AB, Delgado T, Lagunoff M, J. Virol. 91, e02237-16, 2017. https://doi. org/10.1128/JVI.02237-16

Scalise M, Pochini L, Galluccio M, Console L, Indiveri C, Front. Oncol. 7, 306, 2017. https://doi.org/10.3389/ fonc. 2017.00306

Schwenk RW, Holloway GP, Luiken JJFP, Bonen A, Glatz JFC, Prostaglandins Leukot. Essent. Fatty Acids 82, 149-154, 2010. https://doi.org/10.1016/i.plefa.2010.02.029

Serquina AKP, Kambach DM, Sarker O, Ziegelbauer JM, mBio 8, e00576-17, 2017. https://doi.org/10.1128/mBio.00576-17

Shetty M, Maiti B, Shivakumar Santhosh K, Venugopal MN, Karunasagar I, J. Virol. 23, 114-123, 2012. https://doi. org/10.1007/s13337-012-0088-X

Shin YK, Liu Q, Tikoo SK, Babiuk LA, Zhou Y, J. Gen. Virol. 88, 13-18, 2007. https://doi.org/10.1099/vir.0.82419-0

Silva da Costa L, Pereira da Silva AP, Da Poian AT, El-Bacha T, PLoS One 7, e33871, 2012. https://doi.org/10.1371/journal.pone.0033871

Smallwood HS, Duan S, Morfouace M, Rezinciuc S, Shulkin BL, Shelat A, Zink EE, Milasta S, Bajracharya R, Oluwaseum AJ, Roussel MF, Green DR, Pasa-Tolic L, Thomas PG, Cell Rep. 1640-1653, 2017. https://doi.org/10.1016/j. celrep.2017.04.039

Spencer CM, Schafer XL, Moorman NJ, Munger J, J. Virol. 85, 5814-5824, 2011 https://doi.org/10.1128/JVI.02630-10

Su MA, Huang YT, Chen IT, Lee DY, Hsieh YC, Li CY, Ng TH, Liang SY, Lin SY, Huang, SW, Chiang YA, Yu HT, Khoo KH, Chang GD, Lo CF, Wang HC, PLoS Pathog. 10, e1004196, 2014. https://doi.org/10.1371/journal.ppat.1004196

Sun L, Yi L, Zhang C, Liu X, Feng S, Chen W, Lan J, Zhao L, Tu J, Lin L, J. Gen. Virol. 97, 2849-2855, 2016. https://doi. org/10.1099/jgv.0.000597 
Sung WW, Chen PR, Liao MH, Lee JW, Exp. Cell Res. 359, 94-100, 2017. https://doi.org/10.1016/j.yexcr.2017.08.005

Syed GH, Amako Y, Siddiqui A, Trends Endocrinol. Metab. 21, 33-40, 2010. https://doi.org/10.1016/j.tem.2009.07.005

Tang WC, Lin RJ, Liao CL, Lin YL, J. Virol. 88, 6793-6804, 2014. https://doi.org/10.1128/JVI.00045-14

Thai M, Graham NA, Braas D, Nehil M, Komisopoulou E, Kurdistani SK, McCormick F, Graeber TG, Christofk HR, Cell Metab. 19, 694-701, 2014. https://doi.org/10.1016/i. cmet.2014.03.009

Thai M, Thaker SK, Feng J, Du Y, Hu H, Ting Wu T, Graeber TG, Braas D, Christofk HR, Nat. Commun. 6, 8873, 2015. https://doi.org/10.1038/ncomms9873

Thaker SK, Ch'ng J, Christofk HR, BMC Biol.17, 59, 2019a. https:// doi.org/10.1186/s12915-019-0678-9

Thaker SK, Chapa T, Garcia G Jr, Gong D, Schmid EW, Arumugaswami V, Sun R, Christofk HR, Cell Metab. 29, 1206-1216. e4, 2019b. https://doi.org/10.1016/j.cmet.2019.01.024

Tian Y, Jiang W, Gao N, Zhang J, Chen W, Fan D, Zhou D, An J, Biochem. Biophys. Res. Commun. 397, 420-424, 2010. https://doi.org/10.1016/j.bbrc.2010.05.108

Tian X, Zhang K, Min J, Chen C, Cao Y, Ding C, Liu W, Li J, Viruses 11, E1007, 2019. https://doi.org/10.3390/v11050405

Tisoncik-Go J, Gasper DJ, Kyle JE et al., Cell Host Microbe 19, 254266, 2016. https://doi.org/10.1016/i.chom.2016.01.002

Tongluan N, Ramphan S, Wintachai P, Jaresitthikunchai J, Khongwichit S, Wikan N, Rajakam S, Yoksan S, Wongsiriroj N, Roytrakul S, Smith DR, Virol. J. 14, 28, 2017. https://doi.org/10.1186/s12985-017-0685-9

Vander Heiden MG, Cantley LC, Thompson CB, Science 324, 1029-1033, 2009. https://doi.org/10.1126/science. 1160809

Vastag L, Koyuncu E, Grady SL, Shenk TE, Rabinowitz JD, PLoS Pathog. 7, e1002124, 2011. https://doi.org/10.1371/journal.ppat.1002124
Villareal AV, Rodgers MA, Costello DA, Yang PL, Antiviral Res. 124, 110-121, 2015. https://doi.org/10.1016/j.antiviral.2015.10.013

Wakisaka N, Kondo S, Yoshizaki T, Murono S, Furukawa M, Pagano JS, Mol. Cell Biol. 24, 5223-5234, 2004. https:// doi.org/10.1128/MCB.24.12.5223-5234.2004

Wang YQ, Lü L, Weng SP, Huang JN, Chan SM, He JG, Arch. Virol. 152,763-773, 2007. https://doi.org/10.1007/s00705-0060870-4

Warburg O, Posener K, Negelein E, Biochem. Zeitschr. 152, 319-344, 1924.

Wise DR, Ward PS, Shay JES, Cross JR, Gruber JJ, Sachdeva UM, Platt JM, DeMatteo RG, Simon MC, Thompson CB, Proc. Natl. Acad. Sci. USA 108, 19611-19616, 2011. https://doi. org/10.1073/pnas.1117773108

Xiao L, Hu ZY, Dong X, Tan Z, Li W, Tang M, Chen L, Yang L, Tao Y, Jiang Y, Li J, Yi B, Li B, Fan S, You S, Deng X, Hu F, Feng L, Bode AM, Dong Z, Sun LQ, Cao Y, Oncogene 33, 4568-4578, 2014. https://doi.org/10.1038/onc.2014.32

Yan B, Chu H, Yang D, Sze KH, Lai PM, Yuan S, Shuai H, Wang Y, Kao RYT, Chan JFW, Yuen KY, Viruses 11, 73, 2019. https://doi.org/10.3390/v11010073

Yang W, Hood BL, Chadwick SL, Liu S, Watkins SC, Luo G, Conrads TP, Wang T, Hepatology 48, 1396-1403, 2008. https://doi.org/10.1002/hep.22508

Yogev O, Lagos D, Enver T, Boshoff C, PLoS Pathog. 10, e1004400, 2014 https://doi.org/10.1371/journal.ppat.1004400

Yu L, Chen X, Wang L, Chen S, J. Cancer 9, 3699-3706, 2018. https://doi.org/10.7150/jca.27279

Yu Y, Maguire TG, Alwine JC, J. Virol. 85, 1573-1580, 2011. https:// doi.org/10.1128/JVI.01967-10

Yu Y, Maguire TG, Alwine JC, Proc. Natl. Acad. Sci. USA 111, 1951-1956,2014.https://doi.org/10.1073/pnas.1310779111

Zhang J, Jia L, Lin W, Yip YL, Lo KW, Lau VMY, Zhu D, Tsang CM, Zhou Y, Deng W, Lung HL, Lung ML, Cheung LM, Tsao SW, J.Virol. 91, e02168-16, 2017. https://doi.org/10.1128/ JVI.02168-16 